\title{
Dexmedetomidine reduces inflammation in traumatic brain injury by regulating the inflammatory responses of macrophages and splenocytes
}

\author{
MENGYAO DING, YING CHEN, HENGFEI LUAN, XIAOBAO ZHANG, ZHIBIN ZHAO and YONG WU
}

Department of Anesthesiology, The First People's Hospital of Lianyungang, Lianyungang, Jiangsu 222002, P.R. China

Received June 18, 2018; Accepted May 9, 2019

DOI: $10.3892 /$ etm.2019.7790

\begin{abstract}
Traumatic brain injury (TBI) affects people in all demographics, since it is associated with a variety of chronic degenerative diseases, such as Alzheimer's and Parkinson's disease. In TBI, the central nervous system elicits an immune response involving various immune cells that is necessary for healing and defending the body against pathogens, but can also cause secondary damage to the brain if the response is prolonged. In our clinical practice, it has been identified that administration of dexmedetomidine was associated with reduced production of inflammatory cytokines in patients with TBI, which led to the hypothesis that dexmedetomidine may regulate certain inflammatory responses. To test this hypothesis, the roles of dexmedetomidine in the immune system of mice were investigated. Different biological assays were used to assess the influence of dexmedetomidine on the production of inflammatory cytokines, including tumor necrosis factor (TNF)- $\alpha$, interleukin (IL)-6, IL-8 and IL-1 $\beta$. To understand how dexmedetomidine affects different types of immune cells, the influence of dexmedetomidine on splenocytes was also investigated. Finally, the effects of dexmedetomidine on macrophage activation and inflammatory functions were studied. In the present study, clinical observations and in vivo results using a mouse model of TBI revealed the regulatory functions of dexmedetomidine in TBI-associated immune response.
\end{abstract}

\section{Introduction}

Traumatic brain injury (TBI) is of significant public concern since it affects people in all demographics. TBI is usually induced by the occurrence of mechanical forces to the head, which can be followed by loss of consciousness. The severity,

Correspondence to: Dr Yong Wu, Department of Anesthesiology, The First People's Hospital of Lianyungang, 182 Tong Guan North Road, Lianyungang, Jiangsu 222002, P.R. China

E-mail: 18961325621@163.com

Key words: dexmedetomidine, clinical observation, inflammation, traumatic brain injury, cytokines, macrophages pathogenesis, and treatment outcomes of brain trauma are case-dependent. Brain trauma causes millions of deaths worldwide with a tremendous life and economic cost each year (1). Current studies associate TBI with a variety of chronic degenerative diseases, such as Alzheimer's and Parkinson's disease (2). It is necessary to understand the pathological mechanisms of TBI in order to improve the clinical therapeutic strategies for the benefit of patients.

Inflammation is one of the most prominent reactions associated with TBI. When TBI occurs, inflammation is caused by macrophages, microglia and other immune cells, such as monocytes and $\mathrm{T}$ cells, in the central nervous system. In brief, macrophage and microglia in the injured area quickly respond to the injury by sending damage-associated molecular patterns leading to local secretion of cytokines and chemokines (3). These cytokines and chemokines then recruit immune cells such as neutrophils $(4,5)$, which infiltrate injured brain tissues and further promote the secretion of cytokines and cause oxidative stress $(6,7)$. The exact mechanisms of TBI pathogenesis remain undetermined, therefore, one area of focus is the study of the association between neurodegeneration and inflammation, especially modulating traumatic injury, through the adoption of immunosuppressants. The inflammatory responses in TBI are required for healing and defending the body against pathogens; however prolonged inflammation in the injured brain can cause secondary damage. Therefore anti-inflammatory drugs, including corticosteroids, nonsteroidal anti-inflammatory drugs and cytokine inhibitors, have been explored for treating TBI (8) with a significant portion of these treatments able to reduce symptoms and improve brain function.

Dexmedetomidine is an agonist that selectively functions via targeting the 2-adrenergic receptor in the nervous system. In a clinical setting, dexmedetomidine is widely employed for sedating patients who need mechanical ventilation within $24 \mathrm{~h}$ of incidence (9). Dexmedetomidine can modulate the secretions of catecholamines in patients through interacting with the 2-adrenergic receptor. Current studies have also identified the multifaceted protective functions of dexmedetomidine against inflammation (10-12). In vitro studies have demonstrated that dexmedetomidine significantly reduced lipopolysaccharide (LPS)-induced secretion of pro-inflammatory cytokines, such as tumor necrosis factor (TNF)- $\alpha$, interleukin (IL)-6 and IL-8 (13). In clinical 
practice, studies have illustrated similar anti-inflammatory effects although inconsistencies between studies exist (13-18). Dexmedetomidine also reduces patients' need for anesthetic treatment (19), and can reduce the blood pressure and heart rate of patients in a dose-dependent manner (20). Injection of dexmedetomidine prior to surgery can reduce the consumption of oxygen in the intra-operative and post-operative periods (21). In procedural sedation, dexmedetomidine is used for the sedation of non-intubated patients in procedures such as awake carotid endarterectomy and vitreoretinal surgery (22-24). In pediatric practice, dexmedetomidine is also reported to have different clinical sedation effects, although the Food and Drug Administration has not approved it for the pediatric population (25). For example, one study demonstrated that dexmedetomidine could be employed as a primary sedation agent during cardiac catheterization in infants and children (26). In addition, studies have indicated that dexmedetomidine can modulate the immune system; for example, dexmedetomidine protected renal functions in acute kidney injury patients by regulating inflammatory cytokines, such as TNF- $\alpha$ (27), and also demonstrated the ability to reduce the secretion of IL- 6, IL- 8 and TNF- $\alpha$ in critically septic patients (28). Finally, it has been determined that dexmedetomidine treatment reduced secretion of TNF- $\alpha$ and IL- 6 both in plasma and bronchoalveolar lavage fluid of septic mice and inhibited the mRNA expression of toll-like receptor 4 and myeloid differentiation primary response 88 (29).

In our clinical practice, a decreased level of inflammatory cytokines has been identified in TBI patients following dexmedetomidine treatment, thus, it was hypothesized that dexmedetomidine may regulate immune functions. To test this hypothesis, the impact of dexmedetomidine administration on the immune systems of mice was investigated, and specifically, the effect on inflammatory cytokines IL-1 $\beta$, IL-6, IL-8, and TNF- $\alpha$. The influence of dexmedetomidine on splenocytes was also analyzed, in order to understand how dexmedetomidine affects different types of immune cells Finally, how dexmedetomidine regulates macrophage activation and inflammatory function was investigated. The present study may aid in the improved understanding of the regulatory functions of dexmedetomidine in TBI.

\section{Materials and methods}

Animal model. Female C57BL/6J mice (4-7 weeks old, $20 \mathrm{~g}$ weight; 8 mice per group) were purchased from Welitonghua Corporation (Beijing, China). The animals were raised in a room with 12 -h light/dark cycle at $25^{\circ} \mathrm{C}$ with $45 \%$ humidity. The mice had free access to food and water. The TBI model was established as previously reported in the literature (30). In brief, the mice were anesthetized using a mixture of $7.7 \mathrm{mg} / \mathrm{ml}$ ketamine and $12.3 \mathrm{mg} / \mathrm{ml}$ xylazine via intraperitoneal injection. Following shaving the mice, a petroleum-based jelly was put on their eyes to prevent drying. A solution of $10 \%$ iodine and $70 \%$ ethanol was used for cleaning. The head of each mouse was then fixed in a stereotactic frame using ear bars and a bite plate. Scissors were then used to create a longitudinal incision in the middle of each mouse's head and a cotton-tipped applicator was used to expose the skull. Forceps were employed to create pressure on the skull. Following the above operation, an impact system was used to generate a TBI with the actuator set at $3 \mathrm{~m} / \mathrm{sec}$ achieving a $0.8 \mathrm{~mm}$ deformation depth. Following impact, applicators with cotton tips were used to remove any blood, and a warm pad was used to keep the mice warm. When bleeding had ceased, the wound area was sutured and the mice were returned into a clean cage with a warm pad. Mice were treated with $0.05-0.10 \mathrm{mg} / \mathrm{kg}$ buprenorphine via subcutaneous injection every $8 \mathrm{~h}$ for 2 days.

The mice were divided into three groups each containing 8 mice: Naive (mice with no treatment), trauma, and trauma + DEX. Dexmedetomidine (Sigma-Aldrich; Merck KGaA, Darmstadt, Germany) was used at a concentration of $20 \mu \mathrm{g} / \mathrm{kg}$ and was employed to treat mice immediately following trauma induction and was administered through and intravenous (i.v.) tail injection for a single administration (25,31-33). Yohimbine (YOH) was selected as the $\alpha$-2-adrenergic receptor antagonist ( $1 \mathrm{mg} / \mathrm{kg}$; Sigma-Aldrich; Merck KGaA). All the animal experiments were performed under the guidance of the Animal Care and Use Committee at The First People's Hospital of Lianyungang (Lianyungang, China) and approved by the Animal Care and Use Committee. The animal study also followed the local and federal laws and regulations on animal protection.

Patient samples. Patients' samples were collected from The First People's Hospital of Lianyungang between 2012 to 2017. Among the 115 patients (Table I), blood samples from 9 patients were used for cytokine-level tests. Male or female patients aged between 18-75 were selected for the present study. All patients did not have any other treatment at least one month prior to enrollment and exhibited no major disease. Patients who exhibited arrhythmia, renal, liver or heart failure were excluded from the current study. All patients received dexmedetomidine as a normal sedation procedure through i.v. injection at a concentration of $0.2-0.3 \mu \mathrm{g} / \mathrm{kg} / \mathrm{h}$. The treatment was performed immediately after patient admittance and lasted for $\sim 100 \mathrm{~min}$. Notably, these blood samples were not collected specifically for the present study, instead the blood samples were originally collected for various clinical examinations, and the present study obtained permission to use these samples. The samples were not used until written consent was obtained from each patient. The blood samples were centrifuged at $15,000 \times \mathrm{g}$ for $5 \mathrm{~min}$ at $4^{\circ} \mathrm{C}$ to collect the serum, then sealed in a $1.5 \mathrm{ml}$ tube and stored at $-80^{\circ} \mathrm{C}$ prior to ELISA tests. Nine blood samples were also obtained from healthy subjects who were doing blood tests for their annual physical exam. The healthy subjects who participated in the tests were notified about the study, and written permission was obtained. The present study was approved by the Ethics Committee of The First People's Hospital of Lianyungang and followed all the local and federal laws.

ELISA analysis of mouse blood samples. To assess the cytokine levels in mice, blood was collected via retro-orbital collection. In brief, $\sim 100 \mu 1$ blood was collected in heparinized tubes. The blood was then centrifuged at 15,000 x $\mathrm{g}$ for $5 \mathrm{~min}$ at $4^{\circ} \mathrm{C}$ to collect the serum and serum was then stored at $-80^{\circ} \mathrm{C}$. The levels of cytokines IL-6 (cat. no. 550319), IL-8 (cat. no. 555244), and TNF- $\alpha$ (cat. no. 558535) were 
Table I. Clinical characteristics of patients.

\begin{tabular}{lccc}
\hline Clinical characteristics & Group A (age $\leq 50)$ & Group B (age $>50)$ & P-value \\
\hline Gender (male/female) & $13 / 45$ & $10 / 47$ & NS \\
Age & $43.2 \pm 8.2$ & $61.3 \pm 5.1$ & $<0.001$ \\
Systolic blood pressure (mmHg) & $125 \pm 10.3$ & $127 \pm 10.3$ & NS \\
Diastolic blood pressure $(\mathrm{mmHg})$ & $73.9 \pm 7.5$ & $74.9 \pm 6.7$ & NS \\
Smoking & 37 & 35 & NS \\
Alcohol use & 7 & 5 & NS \\
Body mass index $\left(\mathrm{kg} / \mathrm{m}^{2}\right)$ & $23.1 \pm 2.7$ & $25.1 \pm 3.2$ & $\mathrm{NS}$ \\
Blood urine nitrogen $(\mathrm{mg} / \mathrm{dl})$ & $11.5 \pm 3.5$ & $13.5 \pm 5.1$ & NS \\
Total cholesterol $(\mathrm{mg} / \mathrm{dl})$ & $179 \pm 37$ & $191 \pm 29$ & NS \\
High density lipoprotein $(\mathrm{mg} / \mathrm{dl})$ & $51 \pm 12$ & $50 \pm 11$ & NS \\
Fasting blood glucose $(\mathrm{mg} / \mathrm{dl})$ & $72.5 \pm 5.6$ & $79.5 \pm 3.7$ & NS \\
\hline
\end{tabular}

NS, not significant.

determined using ELISA kits (BD Bioscience, San Jose, CA, USA) according to the manufacturer's instructions.

Isolation of splenocytes. Sham mice were anesthetized via gradual exposure to carbon dioxide for 10-15 min. Cervical dislocation was used to ensure a successful sacrifice. The spleen was collected from each mouse, and the tissue forced through a cell strainer $(40 \mu \mathrm{m})$ with a syringe plunger to obtain a cell suspension. EDTA (10 mM) was added to the cell suspension to prevent cells from aggregating. Following PBS washes, the cells were cultured in RPMI culture medium (Thermo Fisher Scientific, Inc., Waltham, MA, USA) supplemented with 2\% fetal calf serum (Sigma-Aldrich; Merck KGaA).

Splenocyte viability assay. For viability tests, cells collected from the spleen were cultured for $12 \mathrm{~h}$. The cells were then washed with PBS twice to remove any debris or free-floating dead cells. Cells were then stained with trypan blue $(1: 1,000$ in PBS) and viable cells were counted using a cell counter.

ELISA analysis of mouse splenocytes. ELISA was used to analyze the levels of cytokines in the splenocyte culture medium. Cells were cultured for $60 \mathrm{~h}$ and $20 \mu \mathrm{l}$ supernatant was collected and centrifuged at $15,000 \times \mathrm{g}$ for $5 \mathrm{~min}$ at $4^{\circ} \mathrm{C}$ to remove the debris. The levels of IL-6 (cat. no. 550319), IL-8 (cat. no. 555244), and TNF- $\alpha$ (cat. no. 558535) were assessed using ELISA kits (BD Bioscience).

Macrophage viability, staining and flow cytometry. Dexmedetomidine and $\mathrm{YOH}$ were used to treat macrophages for viability tests. Macrophages were isolated from mouse bone marrow and cultured in medium, as reported in the literature (34). In brief, macrophages were cultured under standard conditions $\left(5 \% \mathrm{CO}_{2}, 37^{\circ} \mathrm{C}\right)$ in a 96 -well plate $\left(2 \times 10^{5}\right.$ cells per well) and were treated with dexmedetomidine at different concentrations $(10,30$ and $100 \mu \mathrm{g} / \mathrm{ml}), \mathrm{YOH}(10 \mu \mathrm{g} / \mathrm{ml})$, or LPS $(1 \mu \mathrm{g} / \mathrm{ml})$. The cells were cultured for another $24 \mathrm{~h}$, then collected by centrifugation (500 x g for $5 \mathrm{~min}$ ) and washed with PBS twice. Trypan blue (1:1,000 dilution in PBS) was used to stain the cells with the number of viable cells counted using a cell counter.

For flow cytometry assay, macrophages were treated with LPS $(1 \mu \mathrm{g} / \mathrm{ml})$, dexmedetomidine $(30 \mu \mathrm{g} / \mathrm{ml})$, YOH $(10 \mu \mathrm{g} / \mathrm{ml})$, dexmedetomidine $(30 \mu \mathrm{g} / \mathrm{ml})+$ LPS $(1 \mu \mathrm{g} / \mathrm{ml})$, and dexmedetomidine $(100 \mu \mathrm{g} / \mathrm{ml})+\mathrm{LPS}(1 \mu \mathrm{g} / \mathrm{ml})+\mathrm{YOH}(10 \mu \mathrm{g} / \mathrm{ml})$, in 96-well plates ( $1 \times 10^{5}$ cells per well). After $24 \mathrm{~h}$, cells were washed with PBS twice then Fc-block (1:200 in PBS plus 1\% BSA) was added to macrophages for $20 \mathrm{~min}$ at room temperature to prevent non-specific binding. Cells were stained for cluster of differentiation (CD)-80 and CD40 markers to assess the activation levels. Fluorescein isothiocyanate-conjugated CD80 (cat. no. 561954; BD Biosciences) and allophycocyanin-conjugated CD40 (cat. no. 124610; BioLegend, Inc., San Diego, CA, USA) were used diluted at 1:200 in PBS+1\% BSA for $25 \mathrm{~min}$. Following staining, the cells were washed with PBS twice. Cells were then added to PBS with DAPI (1:1,000 dilution) at room temperature, and the levels of surface markers were assessed by flow cytometry (FlowJo V7; FlowJo LLC, Ashland, OR, USA).

Statistical analysis. All data were expressed as average \pm standard error of the mean. The statistical differences between groups were analyzed by unpaired t-tests using GraphPad Prism (v.6.02; GraphPad Software, Inc., La Jolla, CA, USA). Multiple comparisons among groups were analyzed using one-way ANOVA with a Tukey's post-hoc test. $\mathrm{P}<0.05$ was considered to indicate a statistically significant difference.

\section{Results}

No significant difference in clinical characteristics was observed in TBI patients. At our clinical practice, 115 patients who suffered TBI from different causes (i.e., car accident, falling) had their clinical characteristics recorded (Table I). Patients were classified into two groups based on their age for two key reasons: Firstly, aging might have a role in treatment; and secondly, age is a mutually exclusive and a direct parameter for grouping the patients. The following physical 
characteristics were recorded: sex (male/female), age, systolic blood pressure, diastolic blood pressure, smoker, alcohol use, body mass index, blood urine nitrogen, total cholesterol (mg/dl), high-density lipoprotein (mg/dl), and fasting blood glucose $(\mathrm{mg} / \mathrm{dl})$. No statistical difference was observed between these two groups for any parameter (Table I).

Patients with TBI have a higher level of inflammatory cytokines in blood serum. Beyond recording basic clinical characteristics, the aim of the present study was to analyze the levels of inflammatory cytokines present in the blood serum of TBI patients. The levels of IL-1 $\beta$, IL- 6 , IL- 8 and TNF- $\alpha$ were measured $24 \mathrm{~h}$ prior (Trauma group) and $8 \mathrm{~h}$ following the administration of dexmedetomidine (Trauma + Dex group). The cytokine level in healthy people was used as the control (Fig. 1). Trauma patients had significantly higher levels of IL-1 $\beta$ (Fig. 1A), IL-6 (Fig. 1B), IL-8 (Fig. 1C), and TNF- $\alpha$ (Fig. 1D) compared with the healthy control group. However, following dexmedetomidine administration, the levels of IL-1 $\beta$ (Fig. 1A), IL-6 (Fig. 1B), IL-8 (Fig. 1C), and TNF- $\alpha$ (Fig. 1D) were significantly decreased compared with the trauma group. It is of note that the clinical processing of patients with TBI requires complicated procedures, where multiple therapeutic medicines or even surgery might be required. This increased the complexity of the study, therefore the effect of dexmedetomidine administration alone on levels of inflammatory cytokines in these trauma patients could not be fully confirmed. Thus, the effect of dexmedetomidine on TBI in a mouse model was investigated.

Dexmedetomidine regulates the secretion of inflammatory cytokines within $24 \mathrm{~h}$ in a mouse model of TBI. The levels of IL-1 $\beta$, IL-6, IL-8, and TNF- $\alpha$ cytokines were monitored every $8 \mathrm{~h}$ over $24 \mathrm{~h}$ in three groups of mice: naive mice, trauma mice, and trauma mice treated with dexmedetomidine. Levels of IL-1 $\beta$, IL-6, and IL- 8 decreased over $24 \mathrm{~h}$ for trauma mice treated with dexmedetomidine (Fig. 2A-C). It was also observed that the levels of IL- 6 and IL- 8 in the mice with trauma did not vary significantly from 8 to $24 \mathrm{~h}$, indicating that the level of inflammation remained consistent over this period (Fig. 2B and C). There was no significant difference in TNF- $\alpha$ levels between the trauma mice compared with the trauma mice with dexmedetomidine treatment, which indicated that dexmedetomidine did not significantly affect this cytokine in mice (Fig. 2D). The levels of IL-1 $\beta$, IL-6, IL-8 and TNF- $\alpha$ in the three groups of mice were further analyzed at $24 \mathrm{~h}$ following treatment. There was a significant difference $(\mathrm{P}<0.05)$ in the levels of IL-1 $\beta$, IL-6, and IL- 8 between trauma mice and trauma mice with dexmedetomidine treatment (Fig. 2E-G), indicating that dexmedetomidine reduced inflammation in the mice. A somewhat reduced level of TNF- $\alpha$ in the trauma mice with dexmedetomidine treatment compared with trauma mice was observed; however, this difference was not significant (Fig. 2H).

Dexmedetomidine reduces inflammatory cytokine secretion in splenocytes without affecting their viability. Splenocytes were selected for experimentation, as the spleen is a major secondary immune organ and contains different types of immune cells. The spleen has similar structure to a lymph node and has vital roles functioning as part of the mononuclear phagocyte system, metabolizing haemoglobin from red blood cells (35). In addition, the spleen can produce antibodies and remove bacteria or old blood cells. The spleen contains at least half of the monocytes in the body which are capable of differentiating into dendritic cells and macrophages, both of which are vital immune cells (35).

Splenocytes were collected from the spleens of naive mice and processed into a single-cell suspension. It was identified that dexmedetomidine at various concentrations (10, 30 and $100 \mu \mathrm{g} / \mathrm{ml}$ ) and $\mathrm{YOH}$ treatment did not affect the viability of splenocytes (Fig. 3A). Next, the levels of inflammatory cytokines in the different treatment groups were analyzed at $48 \mathrm{~h}$ post-treatment (Fig. 3B-E). Following LPS treatment, increased levels of IL-1 $\beta$, IL- 6 , IL- 8 and TNF- $\alpha$ were observed compared with control untreated cells (Fig. 3B-E). Dexmedetomidine reduced the levels of IL-1 $\beta$, IL- 6 , IL-8 and TNF- $\alpha$, with dexmedetomidine at a higher concentration $(100 \mu \mathrm{g} / \mathrm{ml})$ more effective in reducing inflammation compared with dexmedetomidine at a low concentration $(30 \mu \mathrm{g} / \mathrm{ml}$; Fig. 3B-E). Combination treatment with YOH, dexmedetomidine and LPS resulted in increased secretion of cytokines compared with the samples treated with dexmedetomidine and LPS alone (Fig. 3B-E), suggesting that YOH compromised the anti-inflammatory effects of dexmedetomidine.

Dexmedetomidine regulates the expression of CD40 and CD86 surface markers on macrophages. Macrophages are one of the most important cells that regulate the immune system, therefore the impact of dexmedetomidine on macrophage function was investigated. Results demonstrated that viability was not affected by the various treatments tested in the present study (LPS, dexmedetomidine, dexmedetomidine + LPS, dexmedetomidine + LPS + YOH; Fig. 4A).

The activation of macrophage surface markers was then analyzed by flow cytometry. LPS stimulated the activation of CD40 and CD86 surface markers on macrophages (Fig. 4B-D). By contrast, dexmedetomidine and YOH treatments alone did not stimulate activation of CD40 or CD86 surface markers compared with control, instead displaying similar levels of expression to the control, indicating that these drugs did not promote macrophage activation (Fig. 4D). The use of dexmedetomidine reduced the expression of CD40 and CD86 markers compared with cells treated with LPS alone, which indicated that dexmedetomidine can offset the stimulatory functions of LPS (Fig. 4B-D). Compared with cells treated with LPS + dexmedetomidine, the cells treated with LPS + dexmedetomidin + YOH had increased expression of these surface markers, indicating that $\mathrm{YOH}$ can inhibit dexmedetomidine function (Fig. 4B and C). The percentage of cells expressing CD40 on their cell surface in the CTRL, LPS, dexmedetomidine, YOH, dexmedetomidine + LPS, and dexmedetomidine + LPS + YOH groups was 13.7, 82.3, 11.3, $12.5,58.5$, and $63.9 \%$, respectively (Fig. 4D). The percentage of cells expressing CD86 on their cell surface in the CTRL, LPS, dexmedetomidine, YOH, dexmedetomidine + LPS, and dexmedetomidine + LPS + YOH groups was 12.3, 84.5, 10.2, $9.7,61.1$ and $69.7 \%$, respectively. Taken together, these findings indicated that dexmedetomidine reduced the inflammatory responses of macrophages. 

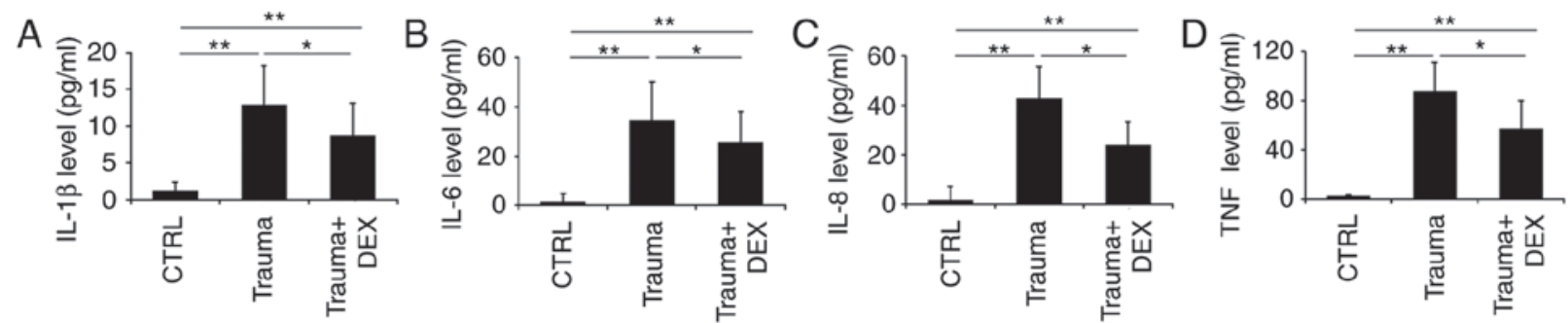

Figure 1. Inflammatory cytokine levels in blood serum of patients. (A) The levels of IL-1 $\beta$, (B) IL-6, (C) IL-8 and (D) TNF- $\alpha$ in control healthy subjects, and TBI patients $24 \mathrm{~h}$ prior to dexmedetomidine treatment and TBI patients following dexmedetomidine treatment, were measured by ELISA. ${ }^{*} \mathrm{P}<0.05$ and ${ }^{* * *} \mathrm{P}<0.01$ with comparisons indicated by lines. IL, interleukin; TNF, tumor necrosis factor; TBI, traumatic brain injury; CTRL, control; DEX, dexmedetomidine.
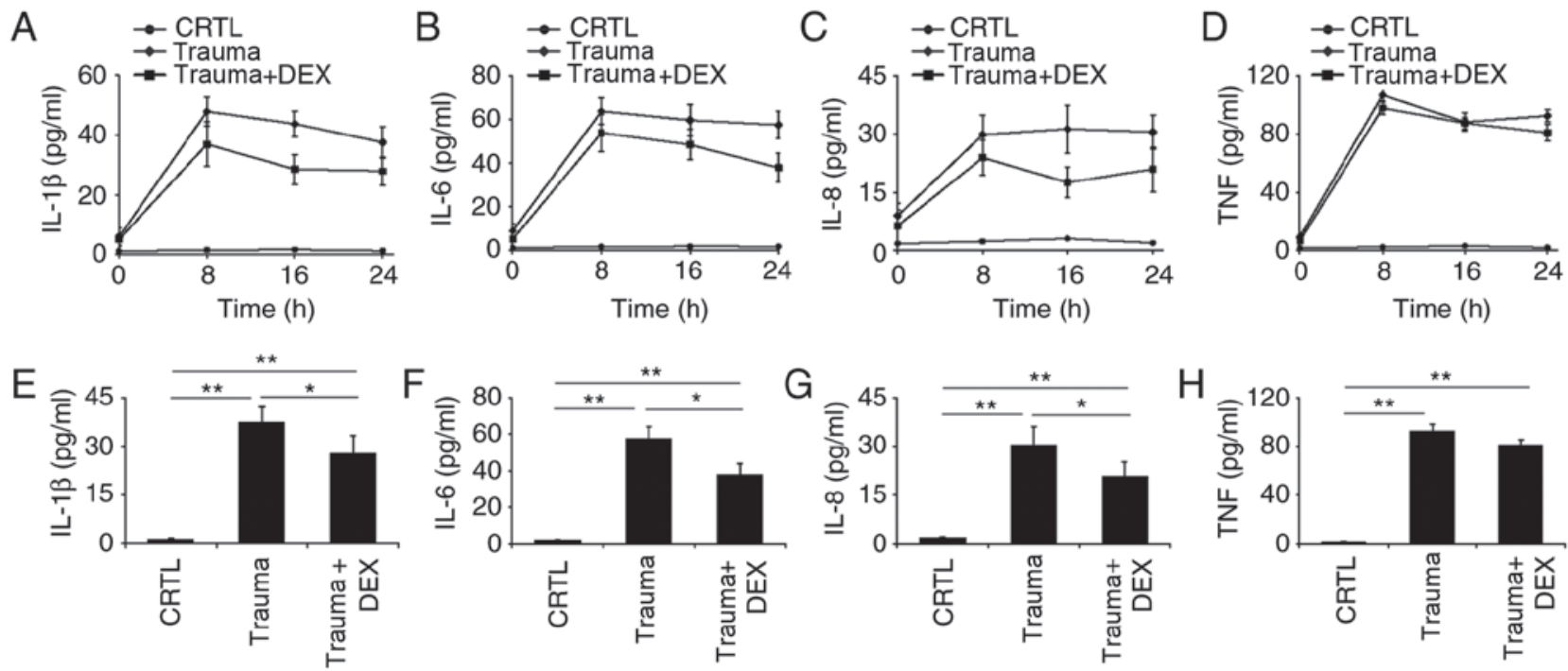

Figure 2. Inflammatory cytokine levels over $24 \mathrm{~h}$ in naive mice (CRTL), mice with brain injury (Trauma), and brain-injured mice with dexmedetomidine treatment (Trauma + Dex). (A) The levels of IL-1ß, (B) IL-6, (C) IL-8 and (D) TNF- $\alpha$ cytokines were measured with ELISA at $0,8,16$ and $24 \mathrm{~h}$ post-injury. (E) Statistical analyses of the levels of IL-1 $\beta,(F)$ IL-6, (G) IL-8 and (H) TNF- $\alpha$ cytokines at 24 h post-injury. ${ }^{*} \mathrm{P}<0.05$ and ${ }^{* *} \mathrm{P}<0.01$ with comparisons indicated by lines. CTRL, control; DEX, dexmedetomidine; IL, interleukin; TNF, tumor necrosis factor.

\section{Discussion}

TBI is typically caused by external forces, such as blast waves, rapid acceleration or deceleration, which leads to temporary or long-term damage to cognitive function. Worldwide, TBI caused $>57$ million hospitalizations and $>10$ million deaths each year $(36,37)$. Clinically, TBI is complicated and usually includes immediate mechanical damage to brain tissues, causing injury to blood vessels and stretching of neurons. Beyond the primary direct damage, TBI also involves secondary damage from the cascades of metabolic and molecular mechanisms, causing neuronal death and tissue damage. In clinical practice, patients may receive different types of treatments to prevent further trauma damage, which may potentially influence the functions of dexmedetomidine. For example, intravenous anesthesia, including ketamine, propofol or etomidate, might be utilized $(38,39)$ which typically will not interact with dexmedetomidine; however detailed interactions require future study. For the animal model of the present study, this factor was not considered since this would make the study excessively complicated. However, to understand the impact of dexmedetomidine comprehensively, future studies need to illustrate the potential influence of other accepted clinical treatments to dexmedetomidine functions.

The present study selected IL-1 $\beta$, IL-6, IL- 8 , and TNF- $\alpha$ as the target cytokines to analyze the roles of dexmedetomidine in modulating inflammation. IL- $1 \beta$ is a key mediator of inflammation in both the peripheral and central nervous systems. The association between IL-1 $\beta$ and TBI has been comprehensively studied in both the focal and diffuse injury models $(40,41)$. In healthy individuals, the levels of IL- $1 \beta$ are barely detectable. By contrast, in TBI patients, the levels of IL-1 $\beta$ increase due to the inflammation (42). Current studies have also identified IL-1 $\beta$ concentrations in post-mortem tissues of TBI patients within several hours of injury occurrence (43). TNF is a multifunctional pro-inflammatory cytokine. Studies using TNF and TNF receptor knockout mice identified that TNF knockout mice with TBI have higher mortality rates and longer recovery times $(44,45)$. IL-6 has been extensively investigated in different physiological and pathophysiological processes, confirming the regulatory roles of IL-6 in inflammation, immunity, and neural development (46). It is of note that IL- 6 is suspected to have vital roles in other diseases, such as autoimmune disease, Alzheimer's disease and TBI, where it is upregulated $(47,48)$. Similarly, 

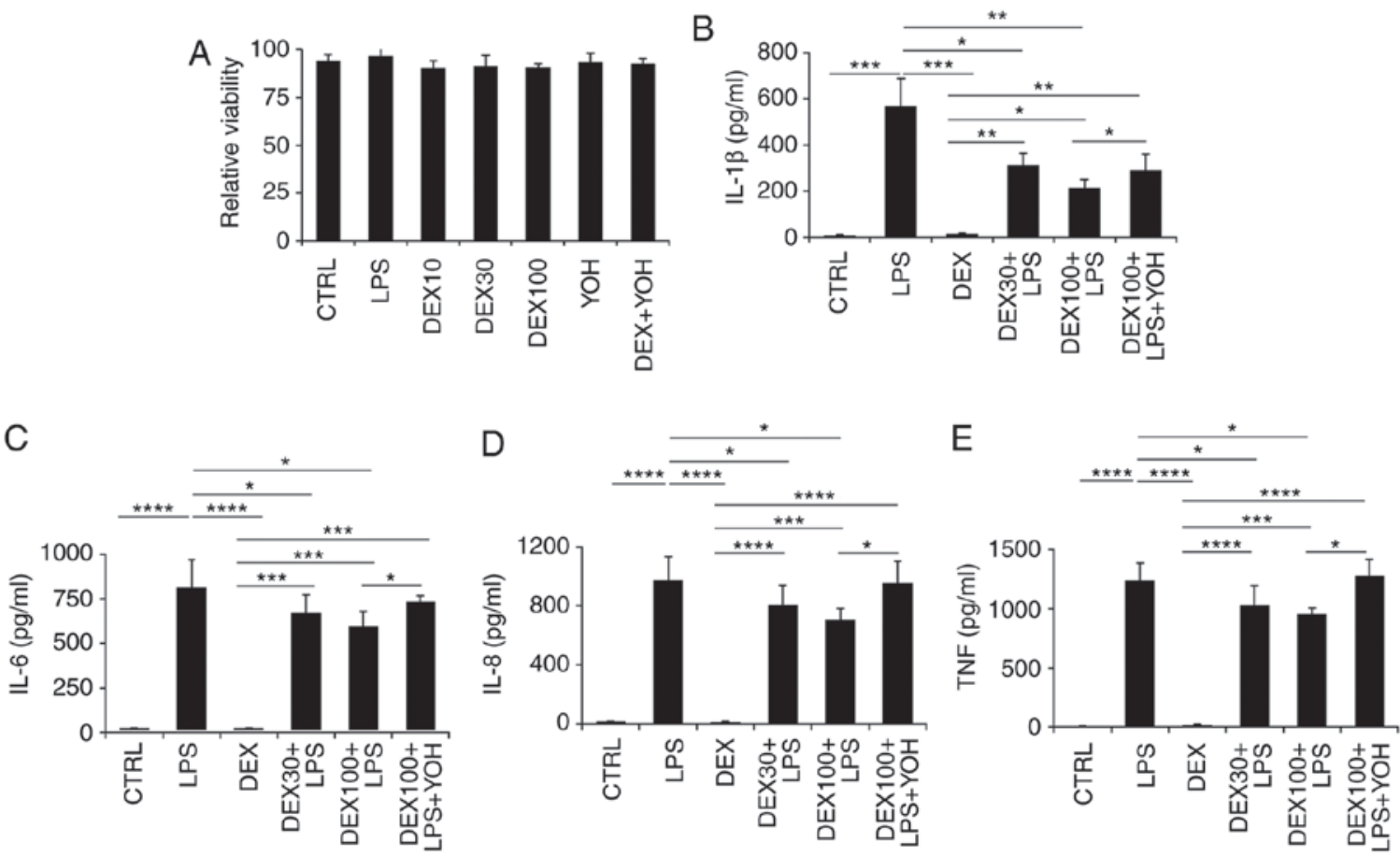

Figure 3. Effect of dexmedetomidine on splenocyte inflammatory cytokine expression. (A) The impact of dexmedetomidine (10, 30, and 100 $\mu \mathrm{g} / \mathrm{ml}$,$) and$ YOH on the viability of splenocytes. (B) The impact of dexmedetomidine (30 and $100 \mu \mathrm{g} / \mathrm{ml}$ ) on the secretion of IL-1 $\beta$, (C) IL-6, (D) IL-8, and (E) TNF- $\alpha$ in splenocytes. LPS was used to stimulate the splenocytes and $\mathrm{YOH}$ was used to compromise the function of dexmedetomidine. ${ }^{*} \mathrm{P}<0.05,{ }^{* *} \mathrm{P}<0.01,{ }^{* * *} \mathrm{P}<0.001$ and ${ }^{* * * * *} \mathrm{P}<0.0001$ with comparisons indicated by lines. YOH, yohimbine; IL, interleukin; TNF, tumor necrosis factor; LPS, lipopolysaccharide; CTRL, control; DEX, dexmedetomidine.
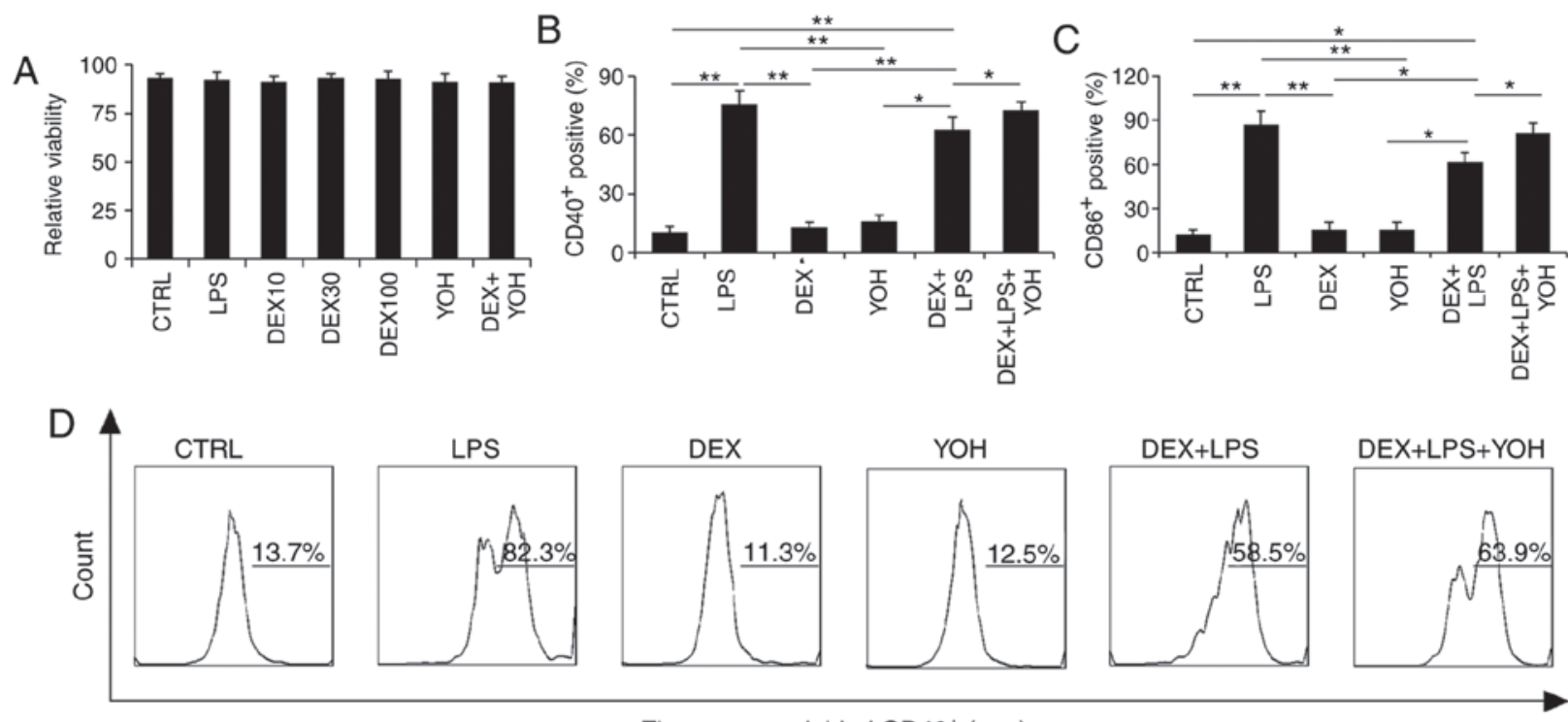

Fluorescence labled $\mathrm{CD}_{40} 0^{+}$(a.u.)
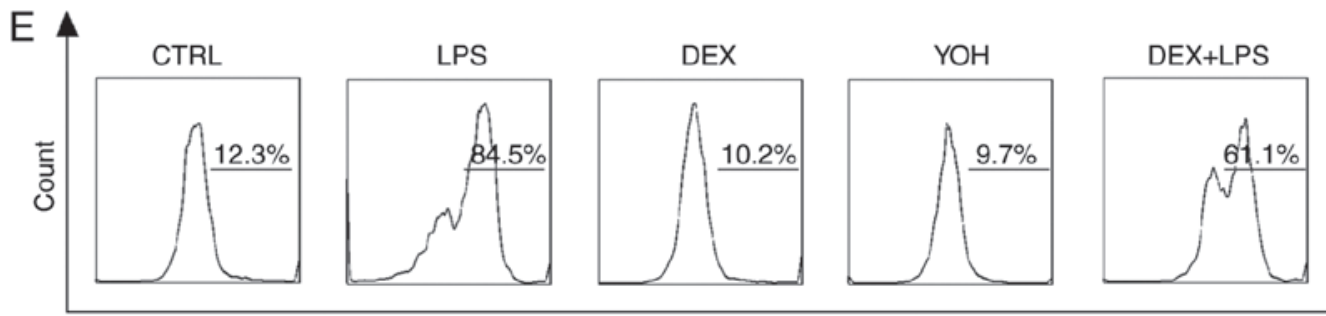

DEX+LPS+YOH

Fluorescence labled CD86+ (a.u.)

Figure 4. Dexmedetomidine regulates the expression of macrophage stimulatory surface markers. (A) Relative macrophage viability following various treatments. (B) Expression of CD40 and (C) CD86 by macrophages following the various treatments. (D) Representative plots from flow cytometry analysis demonstrating the expression of CD40 and (E) CD86. "P<0.05 and ${ }^{* *} \mathrm{P}<0.01$ with comparisons indicated by lines. CD, cluster of differentiation; CTRL, control; LPS, lipopolysaccharide; DEX, dexmedetomidine; YOH, yohimbine. 
studies have demonstrated that levels of the inflammatory cytokine IL-8 peaks following TBI (49). Therefore, the present study investigated these cytokines in both patients and mice with TBI. The current study demonstrated that patients with TBI had a higher level of inflammatory cytokines. The level of inflammatory cytokines decreased over $24 \mathrm{~h}$ following dexmedetomidine treatment. These results are consistent with existing studies that have revealed that the level of inflammatory cytokines including IL-1 $\beta$ and IL-6 increased in patients with TBI $(42,46)$.

The roles of macrophages have been previously studied in central nervous system injury models, such as ischemic stroke and TBI. Necrotic debris clearing and wound repair are vital functions of macrophages (50-52). Studies using different models, such as experimental autoimmune encephalomyelitis, demonstrated that macrophages also regulate the production of IL-10 and transforming growth factor cytokines, indicating that macrophages have different roles in brain injury $(53,54)$. Therefore, the present study selected macrophages as the candidate cell for investigating the roles of dexmedetomidine in the TBI mouse model. The immune system is very complicated with a variety of immune cells therefore the present study focused on investigating the roles of splenocytes and macrophages. These two large types of cells were selected because the spleen is a key secondary immune organ and macrophages have a vital role in regulating inflammation. The present study revealed an enhanced level of inflammatory cytokines in mice stimulated with LPS. These results indicated that the use of dexmedetomidine reduced the level of inflammatory cytokines. Treatment with YOH offset the function of dexmedetomidine and caused an increase in the level of inflammatory response. These results indicated that dexmedetomidine reduced inflammation in patients with TBI, thus providing protection from secondary damage. Additionally, one of the major functions of dexmedetomidine is clinical sedation. The sedative and anti-inflammatory functions indicate that dexmedetomidine is a valuable choice for the treatment of patients with TBI.

Future work will involve analyzing the impact of dexmedetomidine on different types of immune cells, such as regulatory $\mathrm{T}$ cells, cytotoxic $\mathrm{T}$ cells and dendritic cells, in the disease mouse model. In brief, investigation into whether dexmedetomidine has a role in balancing the relative ratios of different types of $\mathrm{T}$ cells and also whether it can impact antigen-presenting functions of dendritic cells is planned. In addition, the present study focused on the impact of dexmedetomidine on the secretion of inflammatory cytokines over $24 \mathrm{~h}$ in the mouse model, since TBI requires fast treatment to the patients; however, the long-term effects of dexmedetomidine also need to be investigated.

In summary, the present study observed decreased levels of inflammatory cytokines following administration of dexmedetomidine in patients with TBI. It was hypothesized that dexmedetomidine could modulate immune functions in TBI. To test this hypothesis, the impact of dexmedetomidine on the production of inflammatory cytokines in mice with TBI was investigated. In addition, the influence of dexmedetomidine on splenocytes was determined to understand how dexmedetomidine affects different types of immune cells. It was demonstrated that dexmedetomidine could downregulate inflammatory cytokines. Finally, how dexmedetomidine mediates macrophage activation and inflammatory cytokine production was determined. The present study provided evidence aiming to better understand the regulatory functions of dexmedetomidine in TBI.

\section{Acknowledgements}

Not applicable.

\section{Funding}

The present study was supported by the First People's Hospital of Lianyungang (grant no. LYG201605).

\section{Availability of data and materials}

All relevant data and its supporting information files are within the present study.

\section{Authors' contribution}

MD and YW designed the experiments and wrote the majority of the paper. MD performed a majority of the experiments. YC, HL and ZZ carried out ELISA experiments and contributed to part of the paper.

\section{Ethics approval and consent to participate}

The patients that participated in the study signed a consent form, allowing the use of their blood samples. The Research Ethics Committee of The First Hospital of Lianyungang approved the study. Protocols involving the use of animals were approved by the Animal Care and Use Committee of The First People's Hospital of Lianyungang.

\section{Patient consent for publication}

Not applicable.

\section{Competing interests}

The authors declare no competing interest.

\section{References}

1. Woodcock T and Morganti-Kossmann MC: The role of markers of inflammation in traumatic brain injury. Front Neurol 4: 18, 2013.

2. Smith DH, Johnson VE and Stewart W: Chronic neuropathologies of single and repetitive TBI: Substrates of dementia? Nat Rev Neurol 9: 211-221, 2013.

3. Russo MV and McGavern DB: Inflammatory neuroprotection following traumatic brain injury. Science 353: 783-785, 2016.

4. Bye N, Habgood MD, Callaway JK, Malakooti N, Potter A, Kossmann T and Morganti-Kossmann MC: Transient neuroprotection by minocycline following traumatic brain injury is associated with attenuated microglial activation but no changes in cell apoptosis or neutrophil infiltration. Exp Neurol 204: 220-233, 2007.

5. Clark RS, Schiding JK, Kaczorowski SL, Marion DW and Kochanek PM: Neutrophil accumulation after traumatic brain injury in rats: Comparison of weight drop and controlled cortical impact models. J Neurotrauma 11: 499-506, 1994. 
6. Dinkel K, Dhabhar FS and Sapolsky RM: Neurotoxic effects of polymorphonuclear granulocytes on hippocampal primary cultures. Proc Natl Acad Sci USA 101: 331-336, 2004

7. Nguyen HX, O'Barr TJ and Anderson AJ: Polymorphonuclear leukocytes promote neurotoxicity through release of matrix metalloproteinases, reactive oxygen species, and TNF-alpha. J Neurochem 102: 900-912, 2007.

8. Bergold PJ: Treatment of traumatic brain injury with anti-inflammatory drugs. Exp Neurol 275: 367-380, 2016.

9. Martin E, Ramsay G, Mantz J and Sum-Ping ST: The role of the alpha2-adrenoceptor agonist dexmedetomidine in postsurgical sedation in the intensive care unit. J Intensive Care Med 18 $29-41,2003$

10. Sukegawa $S$, Higuchi $H$, Inoue $M$, Nagatsuka $H$, Maeda $S$ and Miyawaki T: Locally injected dexmedetomidine inhibits carrageenin-induced inflammatory responses in the injected region. Anesth Analg 118: 473-480, 2014.

11. Taniguchi T, Kidani Y, Kanakura H, Takemoto $\mathrm{Y}$ and Yamamoto K: Effects of dexmedetomidine on mortality rate and inflammatory responses to endotoxin-induced shock in rats. Crit Care Med 32: 1322-1326, 2004.

12. Yagmurdur H, Ozcan N, Dokumaci F, Kilinc K, Yilmaz F and Basar H: Dexmedetomidine reduces the ischemia-reperfusion injury markers during upper extremity surgery with tourniquet. J Hand Surg Am 33: 941-947, 2008.

13. Kawasaki T, Kawasaki C, Ueki M, Hamada K, Habe K and Sata T: Dexmedetomidine suppresses proinflammatory mediator production in human whole blood in vitro. J Trauma Acute Care Surg 74: 1370-1375, 2013

14. Kim Y, Kang SH, Hong TH, Cho ML, Han HJ, Kwon SJ and Lee J: Effects of dexmedetomidine on the ratio of T helper 1 to $\mathrm{T}$ helper 2 cytokines in patients undergoing laparoscopic cholecystectomy. J Clin Anesth 26: 281-285, 2014.

15. Naguib AN, Tobias JD, Hall MW, Cismowski MJ, Miao Y, Barry N, Preston T, Galantowicz M and Hoffman TM: The role of different anesthetic techniques in altering the stress response during cardiac surgery in children: A prospective, double-blinded, and randomized study. Pediatr Crit Care Med 14: 481-490, 2013.

16. Ueki M, Kawasaki T, Habe K, Hamada K, Kawasaki C and Sata T: The effects of dexmedetomidine on inflammatory mediators after cardiopulmonary bypass. Anaesthesia 69: 693-700, 2014.

17. Xia R, Yin H, Xia ZY, Mao QJ, Chen GD and Xu W: Effect of intravenous infusion of dexmedetomidine combined with inhalation of isoflurane on arterial oxygenation and intrapulmonary shunt during single-lung ventilation. Cell Biochem Biophys 67: $1547-1550,2013$

18. Xin J, Zhang YB, Zhou L, Liu F, Zhou X, Liu B and Li Q: Effect of dexmedetomidine infusion for intravenous patient-controlled analgesia on the quality of recovery after laparotomy surgery. Oncotarget 8: 100371-100383, 2017.

19. Aho M, Erkola O, Kallio A, Scheinin H and Korttila K: Dexmedetomidine infusion for maintenance of anesthesia in patients undergoing abdominal hysterectomy. Anesth Analg 75: 940-946, 1992 .

20. Talke P, Richardson CA, Scheinin M and Fisher DM: Postoperative pharmacokinetics and sympatholytic effects of dexmedetomidine. Anesth Analg 85: 1136-1142, 1997.

21. Taittonen MT, Kirrvelä OA, Aantaa R and Kanto JH: Effect of clonidine and dexmedetomidine premedication on perioperative oxygen consumption and haemodynamic state. Br J Anaesth 78 : 400-406, 1997.

22. Bekker A, Gold M, Ahmed R, Kim J, Rockman C, Jacobovitz G, Riles $\mathrm{T}$ and Fisch G: Dexmedetomidine does not increase the incidence of intracarotid shunting in patients undergoing awake carotid endarterectomy. Anesth Analg 103: 955-958, 2006.

23. Bekker AY, Basile J, Gold M, Riles T, Adelman M, Cuff G, Mathew JP and Goldberg JD: Dexmedetomidine for awake carotid endarterectomy: Efficacy, hemodynamic profile, and side effects. J Neurosurg Anesthesiol 16: 126-135, 2004.

24. Kaygusuz K, Gokce G, Gursoy S, Ayan S, Mimaroglu C and Gultekin Y: A comparison of sedation with dexmedetomidine or propofol during shockwave lithotripsy: A randomized controlled trial. Anesth Analg 106: 114-119, table of contents, 2008.

25. Naaz S and Ozair E: Dexmedetomidine in current anaesthesia practice-a review. J Clin Diagn Res 8: GE01-GE04, 2014.

26. Munro HM, Tirotta CF, Felix DE, Lagueruela RG, Madril DR, Zahn EM and Nykanen DG: Initial experience with dexmedetomidine for diagnostic and interventional cardiac catheterization in children. Paediatr Anaesth 17: 109-112, 2007.
27. Tasdogan M, Memis D, Sut N and Yuksel M: Results of a pilot study on the effects of propofol and dexmedetomidine on inflammatory responses and intraabdominal pressure in severe sepsis. J Clin Anesth 21: 394-400, 2009.

28. Memiş D, Hekimoğlu S, Vatan I, Yandim T, Yüksel M and Süt N: Effects of midazolam and dexmedetomidine on inflammatory responses and gastric intramucosal $\mathrm{pH}$ to sepsis, in critically ill patients. Br J Anaesth 98: 550-552, 2007.

29. Zhang J, Wang Z, Wang Y, Zhou G and Li H: The effect of dexmedetomidine on inflammatory response of septic rats. BMC Anesthesiol 15: 68, 2015.

30. Romine J, Gao X and Chen J: Controlled cortical impact model for traumatic brain injury. J Vis Exp: e51781, 2014.

31. Inada T, Sumi C, Hirota K, Shingu K, Okamoto A, Matsuo Y and Kamibayashi T: Mitigation of inflammation using the intravenous anesthetic dexmedetomidine in the mouse air pouch model. Immunopharm Immunot 39: 225-232, 2017.

32. Cagle LA, Franzi LM, Epstein SE, Kass PH, Last JA and Kenyon NJ: Injectable anesthesia for mice: Combined effects of dexmedetomidine, tiletamine-zolazepam, and butorphanol. Anesthesiol Res Pract 2017: 9161040, 2017.

33. Pan W, Hua X, Wang Y, Guo R, Chen J and Mo L: Dose response of dexmedetomidine-induced resistance to hypoxia in mice. Mol Med Rep 14: 3237-3242, 2016.

34. Weischenfeldt $\mathrm{J}$ and Porse B: Bone marrow-derived macrophages (BMM): Isolation and applications. CSH Protoc 2008: pdb prot5080, 2008.

35. Swirski FK, Nahrendorf M, Etzrodt M, Wildgruber M, Cortez-Retamozo V, Panizzi P, Figueiredo JL, Kohler RH, Chudnovskiy A, Waterman P, Aikawa E, et al: Identification of splenic reservoir monocytes and their deployment to inflammatory sites. Science 325: 612-616, 2009.

36. Maas AI, Stocchetti N and Bullock R: Moderate and severe traumatic brain injury in adults. Lancet Neurol 7: 728-741, 2008.

37. Langlois JA, Rutland-Brown W and Wald MM: The epidemiology and impact of traumatic brain injury: A brief overview. J Head Trauma Rehabil 21: 375-378, 2006.

38. Behrens V, Dudaryk R, Nedeff N, Tobin JM and Varon AJ: The ryder cognitive aid checklist for trauma anesthesia. Anesth Analg 122: 1484-1487, 2016.

39. Tobin JM, Grabinsky A, McCunn M, Pittet JF, Smith CE, Murray MJ and Varon AJ: A checklist for trauma and emergency anesthesia. Anesth Analg 117: 1178-1184, 2013.

40. Brough D, Tyrrell PJ and Allan SM: Regulation of interleukin-1 in acute brain injury. Trends Pharmacol Sci 32: 617-622, 2011.

41. Fan L, Young PR, Barone FC, Feuerstein GZ, Smith DH and McIntosh TK: Experimental brain injury induces expression of interleukin-1 beta mRNA in the rat brain. Brain Res Mol Brain Res 30: 125-130, 1995 .

42. Singhal A, Baker AJ, Hare GMT, Reinders FX, Schlichter LC and Moulton RJ: Association between cerebrospinal fluid interleukin- 6 concentrations and outcome after severe human traumatic brain injury. J Neurotrauma 19: 929-937, 2002.

43. Frugier T, Morganti-Kossmann MC, O'Reilly D and McLean CA: In situ detection of inflammatory mediators in post mortem human brain tissue after traumatic injury. J Neurotrauma 27: 497-507, 2010.

44. Scherbel U, Raghupathi R, Nakamura M, Saatman KE, Trojanowski JQ, Neugebauer E, Marino MW and McIntosh TK: Differential acute and chronic responses of tumor necrosis factor-deficient mice to experimental brain injury. Proc Natl Acad Sci USA 96: 8721-8726, 1999.

45. Stahel PF, Shohami E, Younis FM, Kariya K, Otto VI, Lenzlinger PM, Grosjean MB, Eugster HP, Trentz O, Kossmann T, et al: Experimental closed head injury: Analysis of neurological outcome, blood-brain barrier dysfunction, intracranial neutrophil infiltration, and neuronal cell death in mice deficient in genes for pro-inflammatory cytokines. J Cereb Blood Flow Metab 20: 369-380, 2000

46. Romano M, Sironi M, Toniatti C, Polentarutti N, Fruscella P, Ghezzi P, Faggioni R, Luini W, van Hinsbergh V, Sozzani S, et al: Role of IL-6 and its soluble receptor in induction of chemokines and leukocyte recruitment. Immunity 6: 315-325, 1997.

47. Banks WA: Blood-brain barrier transport of cytokines: A mechanism for neuropathology. Curr Pharm Des 11: 973-984, 2005

48. Morganti-Kossmann MC, Kossmann T and Wahl SM: Cytokines and neuropathology. Trends Pharmacol Sci 13: 286-291, 1992.

49. Kushi H, Saito T, Makino K and Hayashi N: IL-8 is a key mediator of neuroinflammation after traumatic brain injury. Crit Care Med 30: A82, 2002. 
50. Dimitrijevic OB, Stamatovic SM, Keep RF and Andjelkovic AV Absence of the chemokine receptor CCR2 protects against cerebral Ischemia/reperfusion injury in mice. Stroke 38: 1345-1353, 2007.

51. Izikson L, Klein RS, Charo IF, Weiner HL and Luster AD: Resistance to experimental autoimmune encephalomyelitis in mice lacking the $\mathrm{CC}$ chemokine receptor (CCR)2. J Exp Med 192: 1075-1080, 2000.

52. Semple BD, Bye N, Rancan M, Ziebell JM and Morganti-Kossmann MC: Role of CCL2 (MCP-1) in traumatic brain injury (TBI): Evidence from severe TBI patients and CCL2-/- mice. J Cerebr Blood Flow Metab 30: 769-782, 2010.
53. Shechter R, London A, Varol C, Raposo C, Cusimano M, Yovel G, Rolls A, Mack M, Pluchino S, Martino G, et al: Infiltrating blood-derived macrophages are vital cells playing an anti-inflammatory role in recovery from spinal cord injury in mice. PLoS Med 6: e1000113, 2009.

54. Weber MS, Prod'homme T, Youssef S, Dunn SE, Rundle CD, Lee L, Patarroyo JC, Stüve O, Sobel RA, Steinman L and Zamvil SS: Type II monocytes modulate T cell-mediated central nervous system autoimmune disease. Nat Med 13: 935-943, 2007. 